\title{
REVISTAS CIENTÍFICAS Y FRAUDES
}

María Pilar Jiménez Aleixandre

Universidade de Santiago de Compostela

En las últimas décadas muchos países han establecido mecanismos de evaluación de la investigación que utilizan como indicadores el número y la calidad de las publicaciones. En nuestra comunidad, didáctica de las ciencias experimentales, ha aumentado exponencialmente la cantidad tanto de países como de personas que investigan y envían artículos a revistas. Sin embargo, el número de revistas del campo que forman parte del Social Sciences Citation Index (SSCI), aun habiendo aumentado, es pequeño, lo que hace más difícil publicar en las de mayor impacto, como Science Education o Journal of Research in Science Teaching, que publican de un 15 a un 20\% de los originales recibidos.

En este contexto, surgen organizaciones, a las que solo cabe definir como fraudulentas, que ponen en marcha revistas en inglés, en muchos casos electrónicas y de acceso libre, y emprenden campañas de captura de incautos a través del correo electrónico (phishing). Algunas campañas son burdas: consisten simplemente en envíos masivos en forma de call for papers a listas de correo de universidades o congresos. Otras son personalizadas: hacen referencia a una comunicación presentada, indicando que les parece interesante y que desearían publicarla. Quizá las investigadoras e investigadores con más experiencia no caigan en estas trampas, pero el hecho de que algunas personas jóvenes manifiesten con alegría "iMe piden un artículo de una revista en inglés!» lleva a pensar que la advertencia es pertinente.

Dos ejemplos de estas revistas y sus webs son:

- Educational Research (de nombre sospechosamente parecido a la prestigiosa Educational Researcher), publicada por International Research Journals, organización con sede en Nigeria, desde septiembre del 2009; <www.interesjournals.org/ER> (mensajes enviados desde <er@interesjournals.com $>\mathrm{y}<$ support.eduresearch@gmail.com>). Su consejo editorial está compuesto por dos editores, Terfot A. Ngwana (University of Lincoln, Reino Unido) y Emmanuel Edoja Achor (Benue State University, Makurdi-Nigeria), ninguno de los dos autor de publicaciones relevantes (del segundo no hemos localizado ninguna). Hay dos editores asociados, pero no consejo asesor: en las normas para autores se indica que pueden sugerir de tres a cinco revisores, lo que no ocurre en las revistas rigurosas. El último párrafo de estas normas indica: «Authors are required to pay a $\$ 400$ processing fee». Un cálculo aproximado de 10 artículos por número por 12 números anuales indica que el negocio rinde 48.000 dólares al año. Multipliquemos esta cantidad por las 28 revistas que publica Interesjournals y obtendremos 1.344.000.

- Global Advanced Research Journal of Educational Research and Reviews, GARJERR (y Global Advanced Research Journal of Social Science), publicada por Global Advanced Research Journals, GARJ, asimismo con sede en Nigeria, desde el 2012, <www.garj.org> (mensajes enviados desde <garjerr@garjournals.org $>$ ), tiene similares características. Su consejo editorial está compuesto por 10 editores, de los que solo 3, según la información de la propia revista, pertenecen a depar- 
tamentos de educación o tienen un doctorado en este campo; los demás son de campos como computer science, electronic business, agricultural economics, etc. Los autores deben pagar 450 dólares, aunque como el número de artículos es menor que en la anterior (aún no han conseguido capturar tantos), su negocio debe de ser menos lucrativo.

En resumen, cuidado con las revistas que solicitan artículos indiscriminadamente, que no están editadas por personas de prestigio en el campo y que requieren un pago. Naturalmente, una publicación que se ha logrado pagando suele carecer de valor académico. Algunos blogs y webs han publicado advertencias sobre estas revistas, por ejemplo Scholarly Open Acces (<http://scholarlyoa. com/2012/03/15/four-new-really-bad-scholarly-open-access-publishers/>) sobre GARJ, EuroJournals y Online Research Journals. Aunque no es el mismo caso, pues no requieren pago, cabe advertir también sobre editoriales como Nova Publishers, que solicitan capítulos para libros que, lejos de constituir un conjunto coherente, son poco más que una amalgama de textos sobre temas dispares (véase una crítica en <http://ktwop.wordpress.com/2011/04/04/beware-nova-publishers-and-frank-or-nadya-columbus-president-and-editor-in-chief/>).

Por otra parte, este tipo de prácticas perjudican a las revistas electrónicas de acceso abierto serias, aquellas que, como la Revista Eureka sobre Enseñanza y Divulgación de las Ciencias (REurEDC), tienen un equipo editorial compuesto por investigadores de prestigio, un proceso de revisión riguroso y un número de artículos fijo, lo que garantiza la selección y, en general, unas normas equivalentes a las de las publicaciones en papel. 


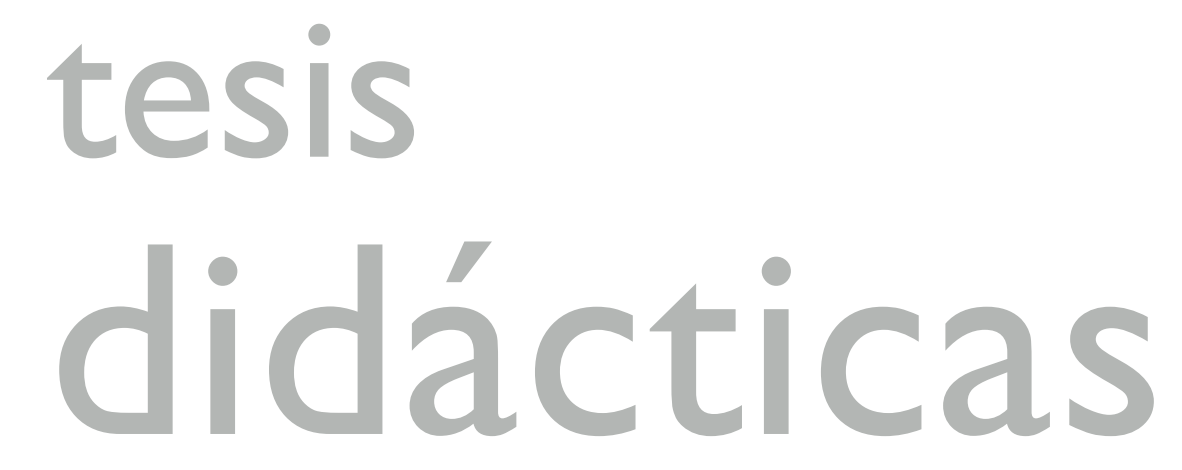

didactcas

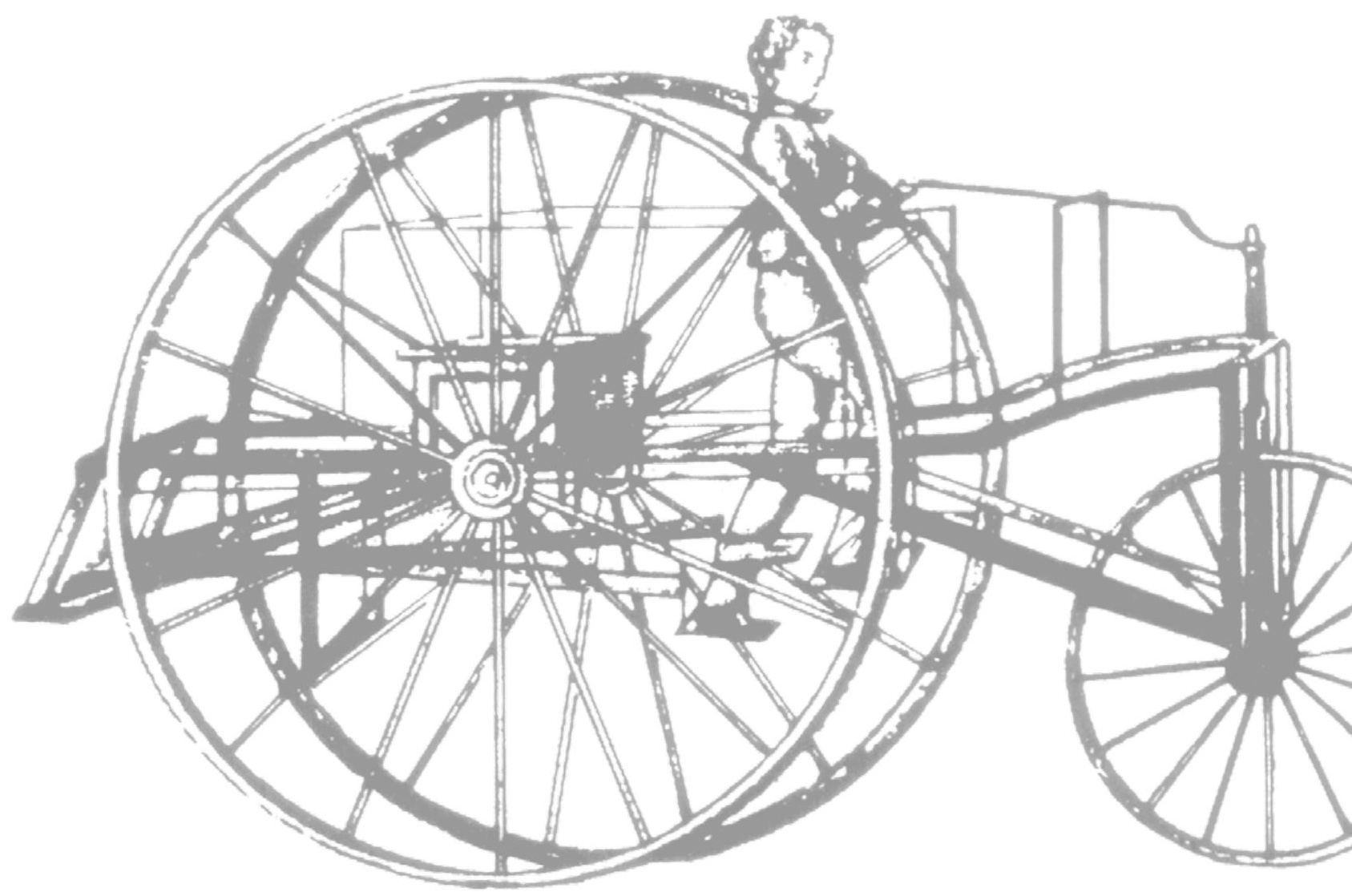


